\title{
QUALIDADE DE MUDAS DE JARACATIÁ SUBMETIDAS A DIFERENTES PERÍODOS DE SOMBREAMENTO EM VIVEIRO'
}

\begin{abstract}
João Paulo Marana², Édison Miglioranza ${ }^{3}$ e Ésio de Pádua Fonseca ${ }^{3}$
RESUMO - Este trabalho teve por objetivo avaliar a influência de diferentes períodos de sombreamento/ sol em mudas de jaracatiá utilizando parâmetros de qualidade. Foram realizadas três avaliações aos 100 , 120, 140 dias após a emergência (DAE), sendo os tratamentos 60, 80, 100 DAE (avaliação 1), 60, 80, 100 e 120 DAE (avaliação 2) e 60, 80, 100, 120 e 140 DAE (avaliação 3) de sombreamento. As mudas de jaracatiá submetidas a diferentes períodos sob condições de sombreamento sofreram alterações nos parâmetros morfológicos e nos índices para avaliação da qualidade. As mudas que ficaram sob maiores períodos de sombreamento aos 100 DAE alcançaram maior altura da parte aérea, maiores relações altura da parte aérea/diâmetro do coleto e da massa de matéria seca da parte aérea/massa de matéria seca do sistema radicular. Nessa avaliação, as plantas apresentaram também os menores valores de diâmetro de coleto, massa de matéria seca do sistema radicular e do Índice de Qualidade de Dickson. O aumento do período de sombreamento refletiu negativamente no desenvolvimento do sistema radicular das mudas aos 100, 120 e 140 DAE. Aos 120 DAE, foram atingidos os padrões de qualidade considerados como mais adequados para o plantio definitivo. O melhor tratamento foi aquele em que as mudas permaneceram 60 dias em sombreamento, seguidos de 60 dias a pleno sol.
\end{abstract}

Palavras-chave: Jacaratia spinosa; Índice de Dickson; Qualidade fisiológica.

\section{QUALITY OF JARACATIA SEEDLING SUBMITTED TO DIFFERENT PERIODS OF SHADE IN NURSERY}

\begin{abstract}
This study aimed to evaluate the influence of different periods of shade/sun in seedlings of jaracatia using quality parameters. Three assessments were performed at 100, 120, 140 days after emergence (DAE), and the treatments 60, 80, 100 DAE (evaluation 1), 60, 80, 100 and 120 DAE (evaluation 2) and 60, 80, 100, 120 and 140 DAE (evaluation 3) were shading. Jaracatia seedlings submitted to different periods under shade conditions had changes in morphological parameters and indices for quality evaluation. Seedlings that were under longer periods of shading at 100 DAE achieved greater shoot height, higher relations of shoot height/stem diameter and dry weight of shoot/dry weight of the root system. In this evaluation, plants also showed the lower diameter of root collar, dry weight of roots and Dickson quality index. Increasing the period of shading reflected negatively on the seedling root system growth at 100 , 120 and 140 DAE. At 120 DAE, the quality standards considered as more suitable for planting were achieved. The best treatment was the one in which the seedlings remained for 60 days in shading followed by 60 days at full sun.
\end{abstract}

Key words: Jacaratia spinosa; Dickson Index; Physiological quality.

\footnotetext{
${ }^{1}$ Recebido em 27.03.2012 aceito para publicação em 15.12.2014.

${ }^{2}$ Universidade Estadual de Londrina, Programa de Pós-graduação em Agronomia, Londrina, Paraná, Brasil. E-mail: <joaomarana@iapar.br>.

${ }^{3}$ Universidade Estadual de Londrina, Departamento de Agronomia, Londrina, Paraná, Brasil. E-mail: <emiglior@uel.br>e <esiof@uel.br>
} 


\section{INTRODUÇ̃̃O}

O jaracatiá (Jacaratia spinosa (Aubl.) A.DC.) é uma árvore da família Caricaceae que apresenta seis gêneros com 35 espécies (BADILLO, 2000), entre elas o mamoeiro (Carica papaya L.), que é a espécie de maior importância econômica no contexto global e, inclusive, para o Brasil, que é o segundo maior produtor mundial (FAOStat, 2012). J. spinosa é nativa da América Central e da América do Sul (CARVALHO; RENNER, 2012). No Brasil, é descrita desde o Ceará (ÉDER-SILVA et al., 2007) até o Rio Grande do Sul (GIEHL; JARENKOW, 2008). É também constatada nos levantamentos da composição florística ou em estudos nos Estados de Minas Gerais (SOARES et al., 2006), São Paulo (PIRATELLI et al., 1998; SILVA; SOARES, 2003), Mato Grosso do Sul (BATTILANI et al., 2005) e Paraná (TOMÉ et al., 1999; TRABAQUINI et al., 2007). Portanto, tratase de uma árvore com ampla distribuição no território nacional, geralmente em fragmentos da Floresta Estacional Semidecidual.

Atualmente, J. spinosa corre o risco de extinção devido à exploração desordenada das florestas, com consequente diminuição da biodiversidade e perdas de recursos genéticos de espécies com elevados valores econômicos (COUTO et al., 2004). Trabaquini et al. (2007), pesquisando sete fragmentos florestais no Norte do Estado do Paraná, encontraram baixa abundância de indivíduos de $J$. spinosa com amplo predomínio de árvores com alta circunferência de caule. Esses resultados, provavelmente advindos das condições de perturbações naturais e antrópicas, indicam alta suscetibilidade à extinção local da espécie, caso ocorra a morte ou o corte dos poucos indivíduos identificados.

A planta e os frutos de jaracatiá apresentam grande potencial de exploração econômica. Os frutos maduros são característicos, lembram um mamão de menor tamanho com coloração amarela e sabor adocicado e podem ser utilizados na fabricação de doces e compotas (PROSPERO, 2010). Na natureza, o fruto é um dos principais alimentos do primata bugio-ruivo, que também dispersa as sementes entre os meses de fevereiro e março, quando os frutos estão maduros (SANTOS et al., 2013). Os frutos verdes produzem látex com ação proteolítica semelhante ao da papaína. Assim, tem potencial de possuir variados usos nas indústrias farmacêuticas, alimentícias, têxteis e cosméticas (GALINDO-ESTRELLA et al., 2009). A parte central do caule pode ser facilmente ralada, lembrando coco ralado, sendo tradicionalmente usada na fabricação de "cocada". Pagamunici (2009) caracterizou o farelo obtido das fibras do caule de jaracatiá e concluiu que o produto tem elevado potencial para ser usado na indústria alimentícia e pode ser adicionado ao iogurte, bolachas e biscoitos. Segundo Muniz et al. (2005), as fibras geram celulose e papel de ótima qualidade e baixo custo, e seu processamento é econômico, rápido e de pouca poluição ambiental-atmosférica.

A propagação do jaracatiá é feita por sementes (FREITAS et al., 2011). Assim, a germinação e o posterior desenvolvimento das mudas assumem especial importância. Uma boa muda é aquela que na época de ser levada para o plantio definitivo no campo apresenta características que permitem máxima taxa de sobrevivência e crescimento inicial rápido. Os parâmetros necessários à obtenção do sucesso do plantio no campo são denominados "índice de qualidade da muda" (FONSECA et al., 2002). Para que esses índices atinjam os valores mínimos exigidos para cada espécie, é necessário conhecer o tamanho e volume do recipiente, o correto manejo da água, adubação ou fertirrigação e o controle da radiação solar.

O manejo da luz, tanto em qualidade (HENRIQUE et al., 2011) quanto em quantidade (TATAGIBA et al., 2010), é decisivo para o crescimento, desenvolvimento e partição de assimilados das plantas em condições de viveiro. Fonseca et al. (2002), estudando o efeito do período de sombreamento sobre o padrão de qualidade de mudas de T. micrantha, determinaram as combinações mais adequadas de tempo de permanência das mudas nas condições de viveiro sombreado, e o tempo de exposição ao pleno sol leva as mudas a atingirem índices de qualidade adequados. Demonstraram que o sistema de raízes foi a parte da planta que sofreu a maior influência do tempo de sombreamento. Quanto maior o período de sombreamento, menor é o crescimento do sistema de raízes e menor o diâmetro do coleto. Também, o aumento do período de sombreamento aumentou a altura e a área foliar, desequilibrando, assim, a partição de assimilados em favor da parte aérea da muda. Com a parte aérea maior há maior perda de água e, sem um sistema radicular adequado, a sobrevivência das mudas após o plantio fica dificultada.

Considerando o risco de extinção do jaracatiá em algumas regiões, a importância que a planta apresenta para a natureza, o grande potencial de uso da espécie

Revista Árvore, Viçosa-MG, v.39, n.2, p.275-282, 2015

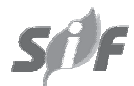


e a falta de conhecimentos produzidos sobre a propagação dessa planta é que foi desenvolvido este trabalho. $\mathrm{O}$ experimento teve como objetivo principal avaliar a influência de diferentes períodos sob condições de sombreamento em mudas de Jacaratia spinosa (Aubl.) A. DC., utilizando parâmetros de qualidade.

\section{MATERIAL E MÉTODOS}

O experimento foi desenvolvido no período de fevereiro a agosto de 2008, no setor de produção de mudas do Centro de Ciências Agrárias da Universidade Estadual de Londrina, em Londrina, Paraná, com latitude $23^{\circ} 23^{\prime}$ S e longitude $51^{\circ} 11^{\prime} \mathrm{W}$. O clima da região é Cfa, segundo a classificação de W. Köppen.

Foram utilizados tubetes $\operatorname{com} 2,65 \mathrm{~cm}$ de diâmetro interno e $12,5 \mathrm{~cm}$ de altura e com $50 \mathrm{~mL}$ de capacidade volumétrica previamente lavados e esterilizados com hipoclorito de sódio $2 \%$ diluído em água na proporção de 1:100 L de água, resultando numa concentração final de $0,02 \%$.

Utilizou-se o substrato comercial Plantmax ${ }^{\circledR}$ (combinação de vermiculita mais compostos orgânicos) acrescido de Osmocote ${ }^{\circledR}$, que é um adubo de liberação lenta (5-6 meses) na dose de $10 \mathrm{~kg} \mathrm{~m}^{-3}$. O substrato apresentava a seguinte composição química: nitrogênio $5,5 \mathrm{cmol}_{\mathrm{c}} \mathrm{dm}^{-3}$; fósforo $2,5 \mathrm{cmol}_{\mathrm{c}}$ $\mathrm{dm}^{-3}$; potássio 4,6 $\mathrm{cmol}_{\mathrm{c}} \mathrm{dm}^{-3}$; cálcio $15,5 \mathrm{cmol}_{\mathrm{c}} \mathrm{dm}^{-3}$; e magnésio $24,7 \mathrm{cmol}_{\mathrm{c}} \mathrm{dm}^{-3}$. Já o Osmocote ${ }^{\circledR}$ apresentava a seguinte composição química: $\mathrm{N}=15 \%$ ( $7 \%$ amoniacal e $8 \%$ nitrato), $\mathrm{P}_{2} \mathrm{O}_{5}=9 \%, \mathrm{~K}_{2} \mathrm{O}=12 \%$, $\mathrm{Ca}=3,5 \%, \mathrm{~S}=2,3 \%, \mathrm{Mg}=1 \%, \mathrm{Fe}=0,45 \%, \mathrm{Mn}=0,06 \%$, $\mathrm{Cu}=0,05 \%, \mathrm{Zn}=0,05 \%$ e $\mathrm{Mo}=0,02 \%$.

Foram coletados frutos maduros para a retirada das sementes de plantas localizadas no Horto Florestal do Instituto Agronômico do Paraná, em Londrina. As sementes foram preparadas, retirando-se manualmente a sarcotesta que as envolvia, assim como descrito por Freitas et al. (2011).

A semeadura foi feita no dia 10 de março de 2008. Como as sementes apresentam germinação lenta e desuniforme, usaram-se três sementes por tubete. Até a emergência, os tubetes foram mantidos no setor de semeadura e germinação, que é protegido com lona plástica transparente e tela de polietileno de coloração preta, com retenção de $48 \%$ da densidade de fluxo radiante solar. O local é provido de sistema de rega suspenso com microaspersores com vazão de $75 \mathrm{~L} \mathrm{~h}^{-1}$, com programação de rega de quatro a cinco vezes ao dia, dependendo da variação da temperatura e umidade relativa do ar.

A emergência teve início aos 21 dias após a semeadura (DAS), e aos 25 DAS as mudas foram levadas para o viveiro coberto com tela de polietileno de coloração preta com $50 \%$ de sombreamento e desbastadas, deixando-se apenas uma muda por tubete seguindo um padrão uniforme de crescimento. Nessa fase, as bandejas planas de polipropileno tiveram sua lotação reduzida de $100 \%$ (176 tubetes) para 50\% (88 tubetes), aumentando o espaço para o desenvolvimento das mudas, reduzindo a competição por luz e aumentando a aeração. Com essa lotação, foi possível distribuir 382 mudas por $\mathrm{m}^{2}$. As regas no setor de crescimento (sombreamento) foram feitas de duas a três vezes ao dia e de três a quatro vezes por dia no setor de aclimatação em pleno sol.

Os tratamentos foram estabelecidos levando em consideração os diferentes períodos de sombreamento (Tabela 1) e adotando o delineamento estatístico inteiramente casualizado, com quatro repetições. Cada repetição correspondeu a uma bandeja com 88 mudas, dispostas na forma retangular ( 8 X 11).

A avaliação da qualidade das mudas ocorreu aos 100, 120 e 140 dias após a emergência (DAE). Em cada uma dessas avaliações, as mudas permaneceram por diferentes períodos sob sombreamento seguidos de diferentes períodos sob pleno sol. A partir dos 60 dias após a emergência, as mudas mantidas sob sombreamento começaram a ser retiradas para o setor a pleno sol, com intervalos de 20 dias entre cada retirada até completar 140 dias após a emergência. A descrição dos tratamentos e os períodos de avaliação estão apresentados na Tabela 2.

Foram calculadas as seguintes características: a) área foliar (AF) expressa $\mathrm{em} \mathrm{cm}^{2}$, estimada com medidor de área foliar LI-COR modelo LI-3000; b) número de folhas (NF); c) altura da parte aérea (APA) expressa em cm, medida com régua milimetrada, a partir da interseção da parte aérea com o nível do substrato; d) diâmetro do coleto (DC), expresso em mm, medido utilizando-se um paquímetro com precisão de $0,01 \mathrm{~mm}$; e) matéria seca de folhas (MSF), matéria seca do caule (MSC) e matéria seca do sistema radicular (MSR), expressas em gramas, secas em estufa de circulação forçada a $75^{\circ} \mathrm{C}$ até peso constante; f) matéria seca total (MST), 
expressa em gramas, obtida pela soma das matérias secas de folhas, caule e raiz; g) RPAR: relação da matéria seca da parte aérea com a matéria seca do sistema radicular; h) RAD: relação da altura parte aérea com o diâmetro do coleto; i) IQD: índice de qualidade de
Dickson obtido pela fórmula IQD = [matéria seca total/ (RAD + RPAR)] (DICKSON et al., 1960).

Os dados foram submetidos à análise de variância e as médias, comparadas pelo teste de Tukey a 5\% de probabilidade de erro.

Tabela 1 - Caracterização dos tratamentos em função do período de permanência das mudas em sombreamento (sombra), aos 100,120 e 140 dias após a emergência.

Table 1 - Treatments depending on the period the seedlings remain under shade at 100, 120 and 140 days after emergence.

\begin{tabular}{|c|c|c|c|c|c|c|}
\hline \multirow{3}{*}{ Tratamento } & \multicolumn{6}{|c|}{ Dias após a emergência } \\
\hline & \multicolumn{2}{|c|}{100} & \multicolumn{2}{|c|}{120} & \multicolumn{2}{|c|}{140} \\
\hline & Sombra(dias) & Sol(dias) & Sombra(dias) & Sol(dias) & Sombra(dias) & Sol(dias) \\
\hline 1 & 60 & 40 & 60 & 60 & 60 & 80 \\
\hline 2 & 80 & 20 & 80 & 40 & 80 & 60 \\
\hline 3 & 100 & 0 & 100 & 20 & 100 & 40 \\
\hline 4 & - & - & 120 & 0 & 120 & 20 \\
\hline 5 & - & - & - & - & 140 & 0 \\
\hline
\end{tabular}

Tabela 2 - Avaliação do diâmetro do coleto (DC), altura da parte aérea (APA), número de folhas (NF), área foliar (AF), massa de matéria seca de folhas (MSF), massa de matéria seca de caules (MSC), massa de matéria seca da parte aérea (MSPA), massa de matéria seca do sistema radicular (MSR), massa de matéria seca total (MST), relação parte aérea/raiz (RPAR), relação altura/diâmetro de coleto (RAD) e índice de qualidade de Dickson (IQD) das mudas de Jacaratia spinosa (Aubl.) A.DC, cultivadas em diferentes períodos sob sombreamento, aos 100, 120 e 140 dias após a emergência.

Table 2 - Root collar diameter (RCD), aerial part height (APH), leaves number (LN), leaf area (LA), dry weight of leaves (DWL), dry weight of stalk (DWS), dry weight of the aerial parts (DWAP), dry weight of the root system (DWRS), total dry weight (TDW), relation aerial parts/root (RAPR), relation height/root collar diameter (RHRCD) and Dickson's quality index (DQI) of the seedlings Jacaratia spinosa (Aubl.) A.DC, cultivated in different periods under shade at 100, 120 and 140 days after emergence.

\begin{tabular}{|c|c|c|c|c|c|c|c|c|c|c|c|c|c|}
\hline Dias & $\begin{array}{l}\text { Somb }^{1} \\
\text { (dias) }\end{array}$ & $\begin{array}{c}\mathrm{DC} \\
(\mathrm{mm})\end{array}$ & $\begin{array}{l}\text { APA } \\
(\mathrm{cm})\end{array}$ & $\begin{array}{c}\mathrm{NF} \\
\text { (unid.) }\end{array}$ & $\begin{array}{c}\mathrm{AF} \\
\left(\mathrm{cm}^{2}\right)\end{array}$ & $\begin{array}{l}\mathrm{MSF} \\
(\mathrm{g})\end{array}$ & $\begin{array}{l}\text { MSC } \\
(\mathrm{g})\end{array}$ & $\begin{array}{c}\text { MSPA } \\
(\mathrm{g})\end{array}$ & $\begin{array}{c}\text { MSR } \\
(\mathrm{g})\end{array}$ & $\begin{array}{l}\text { MST } \\
(\mathrm{g})\end{array}$ & RPAR & RAD & IQD \\
\hline \multirow[t]{5}{*}{100} & 60 & $5,7 \mathrm{Ns}$ & $15,6 \mathrm{~b}$ & $4,5^{\mathrm{NS}}$ & $77,18^{\mathrm{NS}}$ & $0,2822^{\mathrm{NS}}$ & $0,1785^{\mathrm{NS}}$ & $0,4607^{\mathrm{NS}}$ & $0,2672^{\mathrm{NS}}$ & $0,7280^{\mathrm{NS}}$ & $1,98 \mathrm{NS}$ & $2,74 \mathrm{~b}$ & $0,1651^{\mathrm{NS}}$ \\
\hline & 80 & 5,9 & $17,0 \mathrm{ab}$ & 3,5 & 70,29 & 0,2497 & 0,2142 & 0,4640 & 0,3430 & 0,8070 & 1,42 & $2,90 \mathrm{ab}$ & 0,1964 \\
\hline & 100 & 5,2 & $19,3 \mathrm{a}$ & 4,2 & 95,20 & 0,3085 & 0,2127 & 0,5212 & 0,2185 & 0,7398 & 2,53 & $3,67 \mathrm{a}$ & 0,1225 \\
\hline & Média & 5,6 & 17,3 & 4,0 & 80,88 & 0,2801 & 0,2018 & 0,4820 & 0,2762 & 0,7582 & 1,98 & 3,10 & 0,1613 \\
\hline & $\mathrm{CV}(\%)$ & 12,37 & 7,62 & 17,79 & 24,34 & 25,90 & 19,38 & 19,63 & 37,75 & 23,31 & 35,20 & 12,46 & 39,95 \\
\hline \multirow[t]{6}{*}{120} & 60 & $7,6 \mathrm{a}$ & $18,1^{\mathrm{NS}}$ & $4,0^{\mathrm{NS}}$ & $74,60^{\mathrm{NS}}$ & $0,3020^{\mathrm{NS}}$ & $0,3375^{\mathrm{NS}}$ & $0,6395^{\mathrm{NS}}$ & $0,7410 \mathrm{a}$ & $1,38 \mathrm{a}$ & $0,8705 \mathrm{~b}$ & $2,38^{\mathrm{NS}}$ & $0,4245 \mathrm{a}$ \\
\hline & 80 & $6,4 \mathrm{ab}$ & 19,5 & 3,7 & 80,89 & 0,2650 & 0,2742 & 0,5392 & $0,4737 \mathrm{ab}$ & $1,01 \mathrm{a}$ & $1,35 \mathrm{ab}$ & 3,08 & $0,2539 \mathrm{~b}$ \\
\hline & 100 & $6,1 \mathrm{ab}$ & 19,5 & 3,5 & 77,43 & 0,2930 & 0,2667 & 0,5597 & $0,3155 \mathrm{~b}$ & $0,8753 \mathrm{~b}$ & $1,81 \mathrm{a}$ & 3,16 & $0,1767 \mathrm{~b}$ \\
\hline & 120 & $5,7 \mathrm{~b}$ & 15,1 & 3,2 & 72,08 & 0,2607 & 0,1845 & 0,4452 & $0,2942 \mathrm{~b}$ & $0,7395 \mathrm{~b}$ & $1,57 \mathrm{ab}$ & 2,65 & $0,1829 b$ \\
\hline & Média & 6,4 & 18,0 & 3,6 & 76,24 & 0,2801 & 0,2657 & 0,5459 & 0,4561 & 1,00 & 1,40 & 2,82 & 0,2595 \\
\hline & $\mathrm{CV}(\%)$ & 11,38 & 11,93 & 18,89 & 19,53 & 24,70 & 19,40 & 20,97 & 30,83 & 22,50 & 0,5171 & 14,66 & 30,90 \\
\hline \multirow[t]{7}{*}{140} & 60 & $6,9^{\mathrm{NS}}$ & $17,9 \mathrm{NS}$ & $4,2^{\mathrm{NS}}$ & $74,12^{\mathrm{NS}}$ & $0,3320^{\mathrm{NS}}$ & $0,3432^{\mathrm{NS}}$ & $0,6753^{\mathrm{NS}}$ & $0,6070^{\mathrm{NS}}$ & $1,28^{\mathrm{NS}}$ & $1,18^{\mathrm{NS}}$ & $2,58 \mathrm{NS}$ & $0,3413^{\mathrm{NS}}$ \\
\hline & 80 & 7,1 & 20,3 & 4,0 & 77,02 & 0,2922 & 0,3567 & 0,6490 & 0,5850 & 1,23 & 1,12 & 2,84 & 0,3113 \\
\hline & 100 & 7,0 & 21,4 & 4,0 & 92,60 & 0,3590 & 0,3882 & 0,7473 & 0,4843 & 1,23 & 1,74 & 3,04 & 0,2717 \\
\hline & 120 & 7,1 & 21,4 & 4,2 & 87,72 & 0,2942 & 0,3940 & 0,7483 & 0,5483 & 1,29 & 1,73 & 3,15 & 0,3175 \\
\hline & 140 & 6,2 & 19,5 & 3,7 & 60,75 & 0,1992 & 0,2577 & 0,4570 & 0,3850 & 0,8420 & 1,20 & 3,15 & 0,1929 \\
\hline & Média & 6,9 & 20,1 & 4,0 & 78,44 & 0,3073 & 0,3480 & 0,6553 & 0,5219 & 1,17 & 1,39 & 2,95 & 0,2869 \\
\hline & $\mathrm{CV}(\%)$ & 13,24 & 10,93 & 15,93 & 27,30 & 34,85 & 33,21 & 31,30 & 46,45 & 35,50 & 30,00 & 16,61 & 44,71 \\
\hline
\end{tabular}

$\mathrm{CV}(\%)=$ Coeficiente de variação; Sombr ${ }^{1}=$ Sombreamento; ${ }^{\mathrm{NS}}=$ Não significativo. Médias seguidas por diferentes letras minúsculas distintas nas colunas diferem entre si, a $5 \%$ de probabilidade de erro, pelo teste de Tukey.

Revista Árvore, Viçosa-MG, v.39, n.2, p.275-282, 2015 


\section{RESULTADOS}

Os resultados médios do diâmetro de coleto (DC), altura da parte aérea (APA), número de folhas (NF) e área foliar (AF) estão apresentados na Tabela 2. Entre as características avaliadas nas mudas de jaracatiá, o número de folhas e a área foliar não apresentaram diferença significativa nos diferentes períodos sob sombreamento (Tabela 2).

De acordo com os resultados apresentados na Tabela 2, a altura da parte aérea das mudas foi influenciada pelos níveis de sombreamento, apenas após os 100 dias após a emergência (DAE), com valores crescentes, especialmente devido ao baixo índice de luminosidade, que acarreta mudanças morfofisiológicas comuns nas plantas cultivadas sob essas condições.

Para o diâmetro do coleto, foi observada diferença estatística entre os períodos de sombreamento apenas aos 120 DAE. As mudas submetidas a sombreamento por 60 dias foram as que apresentaram o maior valor de diâmetro de coleto de 7,6 mm (Tabela 2).

Entre as demais características, a massa de matéria seca de folhas (MSF), massa de matéria seca de caule (MSC) e massa de matéria seca da parte aérea (MSPA) não apresentaram resultados significativos quando submetidas aos diferentes períodos de sombreamento (Tabela 2). A massa de matéria seca de folhas, mesmo não mostrando diferença estatística, quando calculadas aos 140 dias após a emergência exibiram uma diferença de $66 \%$ entre as médias das mudas calculadas aos 60 e 140 dias de sombreamento.

A massa de matéria seca de raiz e a massa de matéria seca total das mudas aos 120 dias apresentaram médias superiores às demais quando submetidas a 60 dias de sombreamento.

Para a relação massa de matéria seca da parte aérea/ massa de matéria seca do sistema radicular não houve diferença estatística aos 100 e 140 DAE (Tabela 2). Entretanto, aos $100 \mathrm{DAE}$ as mudas apresentaram médias superiores às das demais avaliações.

\section{DISCUSSÃO}

Aos 140 dias após a emergência, as plantas submetidas a diferentes períodos de sombreamento apresentaram a altura da parte aérea de $20,1 \mathrm{~cm}$, em média. Esse valor está na faixa da altura recomendada para mudas de Trema micrantha (L.) Blume, que variam entre 15-23 cm (FONSECA et al., 2002); para café, o ideal foi de 13 a $15 \mathrm{~cm}$, em tubetes de $50 \mathrm{~cm}^{3}$ (MARANA et al., 2008).

Almeida et al. (2005) mostraram que, com 30\% de sombreamento, mudas de Jacaranda puberula (caroba) tiveram maior crescimento em altura com oito meses em viveiro. Mudas de morototó (Schefflera morototoni), outra espécie pioneira, apresentaram alturas crescentes $(77,70 ; 90,00 ; 97,70 ;$ e 98,20 cm) com o aumento do sombreamento $(0 \%, 30,50$ e $70 \%)$, possivelmente em consequência da redução de fotoassimilados e aumento do nível de auxina. Fonseca et al. (2002) também observaram aumento linear significativo na altura da parte aérea com o incremento de permanência das mudas sob sombreamento para Trema micrantha (L.) Blume.

As mudas em geral apresentaram valores de diâmetro de coleto acima de $4,9 \mathrm{~mm}$, sendo, portanto, acima dos 3,2 a 3,5 mm observados nos melhores tratamentos com café (MARANA et al., 2008). Mudas com alto valor de diâmetro de coleto indicaram que haverá boa taxa de sobrevivência após o plantio, conforme Almeida et al. (2005), uma vez que esse é um indicador das taxas de assimilação líquida de produtos da fotossíntese.

Observou-se que houve decréscimo do diâmetro do coleto em função do aumento do período de permanência sob sombreamento aos 100 e 120 dias após a emergência. Resultado esse semelhante ao encontrado por Fonseca et al. (2002), testando diferentes períodos de sombreamento sobre o padrão de qualidade de mudas de Trema micrantha (L.) Blume. Segundo Kozlowski (1962), o aumento do sombreamento diminui a fotossíntese e, consequentemente, a quantidade de fotoassimilados e reguladores de crescimento, causando redução do diâmetro do coleto. Esse autor considera ainda que a fotossíntese, aparentemente, guarda relação mais direta com o crescimento em diâmetro do que em altura.

Aos 120 dias após a emergência, quando se aumenta o nível de sombreamento, ocorre diminuição da massa de matéria seca de caule, raiz e massa de matéria seca total (Tabela 2). Uchida e Campos (2000), avaliando a influência do sombreamento no crescimento de mudas de cumaru (Dipteryx odorata (Aubl.) Willd.-Fabaceae) cultivadas em viveiro, encontraram resultados semelhantes para massa de matéria seca de raiz e massa de matéria seca total. Isso pode ser explicado pela

Revista Árvore, Viçosa-MG, v.39, n.2, p.275-282, 2015 
diminuição na translocação de assimilados para as raízes, já que a luz exerce efeito estimulante nesse processo (SHIROYA et al., 1962).

A luz intensa favorece o desenvolvimento nas folhas, de células empaliçadas e cutículas mais espessas, enquanto o sombreamento favorece a produção de maior quantidade de parênquima lacunoso (KRAMER; KOZLOWSKI, 1972). Ela provoca também aumento da transpiração, propiciando a formação de caules mais espessos e curtos (TOUMEY; KORSTIAN, 1962), aumentando a quantidade de massa de matéria seca total. À medida que diminui a intensidade luminosa, há redução na produção de massa de matéria seca, pois o carboidrato é mais consumido pela respiração do que produzido pela fotossíntese (SALISBURY; ROSS, 1969).

A ausência de diferença significativa entre a massa de matéria seca da parte aérea/massa de matéria seca do sistema radicular indica que as mudas apresentaram o mesmo padrão de distribuição de matéria seca entre os dois órgãos, independentemente do período de permanência sob sombreamento. Fonseca et al. (2002) explicaram tal fato considerando que o maior acúmulo de massa seca da parte aérea pode ser explicado, em parte, pelo pequeno porte e volume do recipiente, o que pode restringir a disponibilidade de água e de nutriente e a expansão do sistema radicular.

Pode-se observar que as mudas com maiores índices de qualidade de Dickson apresentaram maiores valores de diâmetro do coleto, massa seca da parte aérea e do sistema radicular e total e menores valores da relação parte aérea/sistema radicular e da relação altura da parte aérea/diâmetro do coleto. Resultados semelhantes foram encontrados por Fonseca et al. (2002).

Estabelecendo como padrão o valor mínimo do IQD $=0,20$, conforme já usado para coníferas (HUNT, 1990), Trema micrantha (L.) Blume (FONSECA et al., 2002) e também para o cafeeiro (MARANA et al., 2008), observou-se que as mudas de jaracatiá somente atingiram esse valor a partir dos 120 DAE, com 60 e 80 dias sob sombreamento ou 60 e 40 dias sob sol, respectivamente (Tabela 2).

Os parâmetros morfológicos e as relações utilizadas para avaliação da qualidade das mudas não devem ser utilizados isoladamente para classificação do padrão da qualidade de mudas, a fim de que não corra o risco de selecionar mudas mais altas, porém fracas, descartando-se as menores, mas com maior vigor. $\mathrm{O}$ índice de qualidade de Dickson é um bom indicador da qualidade das mudas, pois no seu cálculo são considerados a robustez e o equilíbrio da distribuição da biomassa na muda, ponderando os resultados de vários parâmetros importantes empregados para avaliação da qualidade (FONSECA et al., 2002).

\section{CONCLUSÃO}

As mudas de Jacaratia spinosa (Aubl.) A. DC. submetidas a diferentes períodos sob condições de sombreamento sofreram alterações nos parâmetros morfológicos e nos índices para avaliação da qualidade.

O aumento do período de sombreamento refletiu negativamente no desenvolvimento do sistema de raízes das mudas, aos 100, 120 e 140 dias após a emergência.

As mudas que atingiram padrão de qualidade adequado para o plantio definitivo foram as produzidas com 60 dias de sombreamento, seguidos de 60 dias de sol.

\section{REFERÊNCIAS}

ALMEIDA, L.S.; MAIA, N.; ORTEGA, A.R.; ANGELO, A.C. Crescimento de mudas de Jacaranda puberula Cham. em viveiro, submetidas a diferentes níveis de luminosidade. Ciência Florestal, v.15, n.3, p.323-329, 2005.

BADILlO, V.M. Carica L. vs Vasconcella St. Hil. (Caricaceae): con la rehabilitación de este último. Ernstia, v. 10, p.74-79, 2000.

BATTILANI, J.L.; DIAS, E.S.; SOUZA, A.L.T. Fitossociologia de um trecho da mata ciliar do rio da Prata, Jardim, MS, Brasil. Acta Botânica Brasílica, v. 19, n.3, p.597-608, 2005.

CARVALHO, F.A.; RENNER, S.S. A dated phylogeny of the papaya family (Caricaceae) reveals the crop's closest relatives and the family's biogeographic history. Molecular Phylogenetics and Evolution, v.65, n.1, p.46-53, 2012.

COUTO, J.M.F.; OTONI, W.C.; PINHEIRO, A.L.; FONSECA, É.P. Desinfestação e germinação in vitro de sementes de Mogno (Swietenia macrophylla King). Revista Árvore, v.28, n.5, p.633-42, 2004.

Revista Árvore, Viçosa-MG, v.39, n.2, p.275-282, 2015

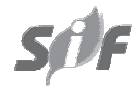


DICKSON, A.; LEAF, A.L.; HOSNER, J.F. Quality appraisal of white spruce and white pine seedling stock in nurseries. Forestry Chronicle, v.36, n. 1, p.10-13, 1960 .

ÉDER-SILVA, E.; FELIX, L.P.; BRUNO, R.L.A. Citogenética de algumas espécies frutíferas nativas do nordeste do Brasil. Revista Brasileira de Fruticultura, v.29. n.1, p.110-114, 2007.

FAOStat, 2012. Statistical databases of the Food and Agriculture Organization of the United Nations. Disponível em: <http:// www.apps.fao.org> Acesso em: 11 maio 2014.

FONSECA, É.P.; VALÉRI, S.V.; MIGLIORANZA, É.; FONSECA, N.A.N.; COUTO, L. Padrão de qualidade de mudas de Trema micrantha (L.) Blume, produzidas sob diferentes períodos de sombreamento. Revista Árvore, v.26, n.4, p.515-523, 2002.

FREITAS, S.J.; BARROSO, D.G.; SILVA, R.F.; MARTINS, V.H.C.R.; FREITAS, M.D S.; FERREIRA, P.R. Métodos de remoção da sarcotesta na germinação de sementes de jaracatiá. Revista Árvore, v.35, n.1, p.91-96, 2011.

GALINDO-ESTRELLA, T.; HERNÁNDEZGUTIÉRREZ, R.; MATEOS-DÍAZ, J.; SANDOVAL-FABIÁN, G.; CHEL-GUERRERO, L.; RODRÍGUEZ-BUENFIL, I.; GALLEGOS-TINTORÉ, S. Proteolytic activity in enzymatic extracts from Carica papaya L. cv. Maradol harvest byproducts. Process Biochemisty, v.44, n.1, p.77-82, 2009.

GIEHL, E.L.H.; JARENKOW, J.A. Gradiente estrutural no componente arbóreo e relação com inundações em uma floresta ribeirinha, rio Uruguai, sul do Brasil. Acta Botanica Brasileira, v.22, n.3, p.741-753, 2008.

HENRIQUE, P.C.; ALVES, J.D.; DEUNER, S.; GOULART, P.F.P.; LIVRAMENTO, D.E. Aspectos fisiológicos do desenvolvimento de mudas de café cultivadas sob telas de diferentes colorações. Pesquisa Agropecuária Brasileira, v.46, n.5, p.458-465, 2011.

HUNT, G.A. Effect of styroblock design and cooper treatment on morphology of conifer seedlings. In: TARGET SEEDLING SYMPOSIUM, MEETING OF THE WESTERN FOREST NURSERY ASSOCIATIONS, GENERAL TECHNICAL REPORT RM-200, 1990, Roseburg. Proceedings... Fort Collins: United States Department of Agriculture, Forest Service, 1990. p.218-222,

KOZLOWSKI, T.T. Tree Growth. New York: The Ronald Press, 1962. p.149-170.

KRAMER, R.J.; KOZLOWSKI, T.T. Fisiologia das árvores. Lisboa: Fundação Calouste Gulbenkian, 1972.755p.

MARANA, J.P.; MIGLIORANZA, É.; FONSECA, É.P.; KAINUMA, R.H. Índices de qualidade e crescimento de mudas de café produzidas em tubetes. Ciência Rural, v.38, n.1, p.39-454, 2008.

MUNIZ, L.F.A.; SOUZA, S.L.; DIAS, C.A.B.; PAVOSKI, L.C.M. Processo econômico de obtenção de celulose e papel à partir de Jaracatia spinosa - Jaracatiá. Revista da Propriedade Industrial, n.1817, p.94, 2005.

PAGAMUNICI, L.M. Utilização da fibra de jaracatiá no enriquecimento do iogurte. 2009.112f. Dissertação (Mestrado em Ciência e Tecnologia de Alimentos) - Universidade Estadual de Londrina, Londrina, 2009.

PIRATELLI, A.J.; PINÃ-RODRIGUES, F.C.M.; GANDARA, F.B.; SANTOS, E.M.G.; COSTA, L.G.S. Biologia da polinização de Jacaratia spinosa (Aubl.) A.DC.(Caricaceae) em mata residual do sudeste brasileiro. Revista Brasileira de Biologia, v.58, n.4, p.671-679, 1998.

PROSPERO, E. T. P. Caracterização da fruta do Jacaratia spinosa e processamento do doce de jaracatiá em calda com avaliação de estabilidade. 2010. 138f. Dissertação (Mestrado em Ciência e Tecnologia de Alimentos) - Escola Superior de Agricultura "Luiz de Queiroz", Piracicaba, 2010.

SALISBURY, F.B.; ROSS, C. Carbon dioxide fixations and photosynthesis in nature. In SALISBURY, F.B.; ROSS, C.W. Plant physiology. Belmont: Wadsworth, 1969. p.93-95.

Revista Árvore, Viçosa-MG, v.39, n.2, p.275-282, 2015 
SANTOS, G.A.S.D.; BIANCHINI, E.; REIS, N.R. Seasonal variation of consumption of the species used as fruit source by brown howler monkey (Allouata clamitans) in southern Brazil. Biota Neotropica, v.13, n.3, p.148-153, 2013.

SHIROYA, T.; LISTER, G.R.; SLANKIS, V.; KROTKOV, G.; NELSON, C.D. Translocation of the products of photosynthesis to roots of pine seedlings. Canadian Journal of Botany, v.40, n.8, p.1125-1135, 1962.

SILVA, L.A.; SOARES, J.J. Composição florística de um fragmento de floresta estacional semidecídua no município de São Carlos-SP. Revista Árvore, v.27, n.5, p.647-656, 2003.

SOARES, M.P.; SAPORETTI JR., A.W.; MEIRA NETO, J.A.A.; SILVA, A.F.; SOUZA, A.L. Composição florística do estrato arbóreo de floresta Atlântica Interiorana em Araponga Minas Gerais. Revista Árvore, v.30, n.5, p.859-870, 2006.

TATAGIBA, S.D.; PEZZOPANE, J.E.M.; REIS, E.F. Crescimento vegetativo de mudas de café arábica
(Coffea arabica L.) submetidas a diferentes níveis de sombreamento. Coffea Science, v.5, n.3, p.251-261, 2010.

TOMÉ, M.V.D.F.; MIGLIORANZA, E.; VILHENA, A.H.T.; FONSECA, E.P. Composição florística e fitossociológica do Parque Estadual Mata São Francisco. Revista do Instituto Florestal, v.11, n.1, p.13-23, 1999.

TOUMEY, J. W.; KORSTIAN, C. F.

Foundations of silviculture upon an ecological basis. New York: J. Wiley, 1962. $468 \mathrm{p}$.

TRABAQUINI, K.; MIGLIORANZA, É.; FRANÇA, V.; VIEIRA, A.O.S. Análise espacial de fragmentos florestais com ocorrência de jaracatiá no norte do Paraná - Brasil. RA'E GA, v.14, p.193-203, 2007.

UCHIDA, T.; CAMPOS, M.A.A. Influência do sombreamento no desenvolvimento de mudas de cumaru (Dipteryx odorata (Aubl.) Willd. Fabaceae), cultivadas em viveiro. Acta Amazonica, v.30, n.1, p.107-113, 2000. 